\title{
A synthesis and comparative evaluation of factors influencing the effectiveness of drainage water management
}

Jared A. Ross ${ }^{\mathrm{a}, \mathrm{g}}$ e-mail: jared.ross@tnc.org

Matthew E. Herbert ${ }^{\mathrm{a}}$ e-mail: mherbert@tnc.org

Scott P. Sowa ${ }^{a}$ e-mail: ssowa@tnc.org

Jane R. Frankenberger ${ }^{\mathrm{b}}$ e-mail: frankenb@purdue.edu

Kevin W. King ${ }^{c}$ e-mail: kevin.king@ars.usda.gov

Sheila F. Christopher ${ }^{\mathrm{d}}$ e-mail: sheila.christopher@ nd.edu

Jennifer L. Tank ${ }^{\mathrm{d}}$ e-mail: tank.1@ @ nd.edu

Jeffrey G. Arnold e-mail: jeff.arnold@ @ars.usda.gov

Mike J. White e-mail: mike.white@ars.usda.gov

Haw Yen ${ }^{\mathrm{f}}$ e-mail: $\underline{\text { hyen@ @brc.tamus.edu }}$

${ }^{\mathrm{a}}$ The Nature Conservancy, 101 E. Grand River Ave., Lansing, MI 48906 USA

${ }^{\mathrm{b}}$ Purdue University, Department of Agricultural and Biological Engineering, 225 S. University

St., West Lafayette, IN 47907 USA

${ }^{\mathrm{c}}$ USDA-ARS, Soil Drainage Research Unit, 590 Woody Hayes Dr., Columbus, OH 43210 USA

${ }^{\mathrm{d}}$ University of Notre Dame, Department of Biological Sciences, 192 Galvin Life Science Center,

Notre Dame, IN 46556 USA

${ }^{\mathrm{e} U S D A-A R S, ~ G r a s s l a n d ~ S o i l ~ a n d ~ W a t e r ~ R e s e a r c h ~ L a b o r a t o r y, ~} 808$ East Blackland Rd., Temple, TX 76502 USA

f Texas A\&M University, Blackland Research \& Extension Center, 720 East Blackland Rd., Temple, TX 76502 USA

${ }^{\mathrm{g}}$ Corresponding author 


\section{Abstract}

2 Viable large-scale crop production in the United States requires artificial drainage in humid and

3 poorly drained agricultural regions. Excess water removal is generally achieved by installing tile

4 drains that export water to open ditches that eventually flow into streams. Drainage water

5 management (DWM) is a conservation practice that allows farmers to artificially raise the outlet

6 elevation of a field's drain tile and can reduce nutrient loss during wet periods by storing more

7 water in the field. We intended to assess the effectiveness of DWM to reduce drainage discharge

8 and nutrient loads and additionally identify predictor variables that influence DWM

9 effectiveness. We compared managed (i.e., DWM) and free draining records using paired t-tests,

10 and identified factors associated with DWM effectiveness using a multiple linear regression

11 approach. T-test results indicated that DWM was highly effective in reducing drainage water

12 discharge and nutrient losses via drain tiles as tile discharge volumes were reduced on average

$1346 \%$, while tile nitrate loads were reduced by $48 \%$. In addition, total phosphorus and dissolved

14 reactive phosphorus loads were reduced by $55 \%$ and $57 \%$, respectively. Based on regression

15 results, we found that several aspects of farm and tile drain management were associated with

16 DWM effectiveness, while site specific landscape characteristics were less likely to predict

17 effectiveness. While DWM is effective as a conservation practice to reduce discharges of water

18 and nutrients from drain tiles, we also identified several knowledge gaps. Future research should

19 investigate effects of DWM on water and nutrients lost in other pathways such as surface runoff,

20 preferential flow, groundwater recharge and biological uptake, and also focus more attention on

21 phosphorus as there is a paucity of research on this topic.

22 Keywords: Agricultural drainage, Surface runoff, Nitrate-nitrogen, Dissolved reactive

23 phosphorus, Total phosphorus, Water quality 


\section{Introduction}

Consistent and profitable large-scale crop production in the United States has in part

26 relied upon artificial (tile) drainage, as some of the most fertile soils are found in humid climates

27 and are naturally poorly drained (Fausey et al. 1995). Artificial drainage is achieved by

28 installing subsurface pipes (i.e., tile drains) that help to export excess soil water to drainage

29 ditches that eventually flow into streams. While artificial drainage has led to increased crop

30 yields, as well as reductions in surface runoff and associated sediment loss (Skaggs et al. 1982),

31 it has also contributed to extensive alterations in watershed hydrology and increased transport of

32 nutrients from farm fields into surface waters (Blann et al. 2009). Increased nutrient loading to

33 streams degrades water quality leading to eutrophication of marine and freshwater bodies. This

34 promotes harmful algal blooms (HABs) and subsequent hypoxic and anoxic conditions,

35 including those often found in the Gulf of Mexico and shallow portions of the Great Lakes

36 (David et al. 2010, Smith et al. 2015). These water quality impacts degrade biological integrity

37 in streams and receiving waters (Ludsin et al. 2001, Miltner 2010, Weigel and Robertson 2007)

38 and impact ecological services such as safe drinking water and productive fisheries (Breitburg et

39 al. 2009, Ludsin et al. 2001, Smith et al. 2015).

Drainage water management (DWM), also referred to as controlled drainage, is an

41 agricultural conservation practice that allows tile outlet elevations to be managed. By adding

42 and removing control structures such as weir boards, subsurface drainage is restricted or

43 promoted by raising and lowering tile outlet elevations (Frankenberger et al. 2006). Drainage

44 water management is gaining popularity and being increasingly implemented in the Midwestern

45 U.S. and has received considerable attention in the scientific literature (e.g., Adeuya et al. 2012,

46 Fausey 2005, Jaynes 2012). Current estimates of land under DWM are not available; however, 
47 the implementation of DWM is increasing as a result of water quality concerns. Additionally,

48 state and federal cost share opportunities have contributed to increased implementation of the

49 practice (e.g., Environmental Quality Incentives Program; Minnesota's Clean Water Fund).

50 Many studies have documented that this practice can effectively reduce drainage outflow and

51 nutrient loading from tiles across a range of geographic regions (Skaggs et al. 2012). With the

52 growing body of data and information on DWM comes the opportunity — as well as the need-

53 for synthesizing and evaluating the performance of the practice across these studies.

$54 \quad$ Our main goal is to assess the performance of DWM as a conservation practice intended

55 to reduce losses of water and nutrients (i.e., nitrogen $(\mathrm{N})$ and phosphorus $(\mathrm{P}))$ from tile discharge

56 while also considering subsequent changes in surface runoff due to DWM. In our analysis we:

57 1) compare managed and free draining observations to evaluate the effectiveness of DWM, and

58 2) identify site-specific landscape (e.g., climate, weather, and topography) and farm and tile

59 drain management factors (e.g., nutrient application rate, drain spacing, drain depth, timing of

60 managing tiles) potentially important in influencing the effectiveness of DWM. Our review also

61 takes note of key knowledge gaps that have not been sufficiently addressed in previous studies in

62 an effort to guide future research toward influences of DWM that are currently unclear.

\section{2. Methods}

\subsection{Literature review and article selection criteria}

We searched for both measured and modeled studies evaluating the effects of DWM on

66 water quantity and quality in surface runoff and tile discharge from plots, fields, or small

67 watersheds. For any particular study to be included, it had to assess the influence of DWM

68 compared to free draining tiles, and report quantitative values or easily interpretable graphs of at 
69 least one response variable of interest. We used literature database search engines, primarily

70 Google Scholar and to a limited extent, Web of Science in our literature search. We used a

71 variety of keywords related to drainage control including but not limited to: controlled drainage,

72 drainage water management, and tile drain management. We considered research from any time

73 period located in any tile drained landscapes flowing into a drainage network. We additionally

74 searched for technical reports, symposium papers, and investigated references from both reviews

75 and the selected papers to identify relevant research not initially obtained in our literature search.

76 Water quantity and quality response variables of interest included: discharge (surface

77 runoff and tile drainage), and annual nutrient loads (nitrate-nitrogen, dissolved reactive

78 phosphorus, and total phosphorus) in both surface runoff and tile drainage.

79 We had concerns of confounding effects with studies where sub-irrigation was used

80 concurrently with DWM as details regarding implementation of this practice was either not

81 reported (e.g., volume applied) and/or would likely have an influence on drain flow and nutrient

82 loads because of the added water and the increased crop growth due to irrigation. Because of

83 this, we continued to analyze only those observations that did not employ sub-irrigation. All

84 successive methods and results presented will focus on the use of DWM without the use of sub-

85 irrigation.

\subsection{Database organization}

Depending on how data were reported, we considered individual treatments unique

88 observations within the database. For example, if a study reported the average of multiple plots

89 or perhaps the average annual value over multiple years from a single or multiple plots, we

90 treated this as a single observation (i.e., one single row) within the database. In contrast, if a 
91 study reported individual values from multiple plots or years, we treated these as separate

92 observations within the database to maximize the sample size available for subsequent analyses.

93 To support our first objective, we paired individual observations to be compared for differences.

94 For example, if a study compared free with managed drains across multiple plots or years, but

95 reported each plot or year separately, we paired free and DWM data from each corresponding

96 plot or year.

97 We calculated the percent (\%) reduction from free drainage to DWM from each pair of

98 observations. If a study reported \% reduction of a particular response variable of interest, but

99 raw data values used to calculate the \% reduction were not clearly reported or were displayed in

100 a coarse graphical format, we extracted only the \% reduction for subsequent analyses. Reporting

101 of the \% reduction in flow or nutrients as a result of using DWM is common in the literature

102 (Skaggs et al. 2012), and provides a measure of DWM performance that is relative to traditional

103 drainage performance under the same conditions. Additionally, we feel that a standardized \%

104 reduction provides a more comparable response variable than raw hydrologic and nutrient load

105 values, given the range of conditions from which synthesized data were collected. Treating \%

106 reduction as a measure of performance allowed us to address our second objective which was to

107 identify site specific landscape and farm and tile drain management variables that are potentially

108 important in influencing DWM performance.

\subsection{Data analyses}

To determine whether the use of DWM was effective in altering water quality and

111 quantity relative to free drainage, regardless of site specific landscape and farm and tile drain

112 management practices, we performed two paired t-tests for each response variable using the 
113 paired observations described above. The first set of paired t-tests only used data from

114 empirically measured studies, while the second set combined measured and modeled studies

115 together. Combining measured and modeled data together provided DWM influences to be

116 synthesized from a larger pool of studies than using measured data alone, and also gave us the

117 opportunity to explore whether impacts from DWM are consistent across each type of

118 investigation. Due to the lack of data characterizing the effect of DWM on phosphorus loads, an

119 a priori decision was made to use a significance level of $\mathrm{P} \leq 0.10$ for $\mathrm{P}$ analyses. As weather

120 patterns and drain management strategies often differ between the growing and non-growing

121 seasons, we also performed separate t-tests on measured tile discharge and tile $\mathrm{NO}_{3}{ }^{-} \mathrm{N}$ loads for

122 growing season alone, as well as non-growing season alone when data were partitioned between 123 seasons.

124 We identified potentially important site specific landscape and farm and tile drain 125 management predictor variables from articles discovered through our literature search (Table 1).

126 We wanted to account for differences in study location conditions by gathering a variety of

127 potentially important predictive information ranging from long-term regional characteristics

128 (e.g., mean regional precipitation) to site specific natural (e.g., soil texture) and farm

129 management attributes (e.g., crop type). Predictor variable reduction began by excluding those

130 that had $>30 \%$ missing values in our compiled dataset. Next, a Pearson's correlation analysis

131 was performed on the remaining predictor variables to reduce redundancy. If a pair of variables

132 were highly correlated (i.e., Pearson's $r=$ absolute value $>0.70$ ), one was retained based on its

133 ecological relevance (e.g., when highly correlated, precipitation during the study would be

134 chosen over average regional precipitation). 
136 response variables with site specific landscape and farm and tile drain management factors (i.e.,

137 potential predictors). We used \% reduction of flow and nutrient loads as our response variables.

138 We performed separate regressions on each response variable to identify predictor variables that

139 are influential in affecting the performance of DWM to reduce discharge of water and nutrients.

140 This approach tests whether statistically significant relationships exist between each response

141 variable of interest with a suite of potential predictors. We argue that significantly associated

142 predictor variables have the potential to affect the ability of DWM to reduce discharge of water

143 and nutrients. We used a stepwise variable selection procedure to identify influential predictor

144 variables, and we used a pairwise deletion approach to missing data. Unlike listwise deletion

145 that only takes into account observations having a complete set of data, a pairwise approach

146 maximizes the available data by considering observations that may have missing data for one or

147 more potential predictors. After we identified predictor variables, we assessed multi-collinearity

148 based on a variance inflation factor threshold of four (VIF < 4), and any models with variables

149 exceeding this threshold were not considered for further reporting. Multicollinearity occurs

150 when multiple predictor variables are highly correlated among each other. High multicollinearity

151 among predictors within a regression model can result in increased variation in estimates of

152 regression coefficients for predictor variables. This can lead to unwarranted relationships to be

153 inferred between predictors and the response variable of interest. Variance inflation factors are

154 calculated for each predictor variable, and determine the amount of increased variance in

155 estimated coefficients due to multicollinearity. Rules of thumb regarding the use of VIFs to

156 indicate multicollinearity problems have commonly been suggested as high as 10 (e.g., Hair et al.

157 1995; Chatterjee et al. 2000), so our threshold of 4 is somewhat conservative. If multiple models 
158 were still available after investigating collinearity issues, we selected the one with the lowest

159 Akaike Information Criterion (AIC) (Akaike 1973) as the best model. The AIC selection

160 approach quantifies the quality of models relative to other models produced with the same

161 dataset. The goodness of fit of a particular model is weighed against the number of predictors

162 included by selecting the one that fits relatively well but contains the least number of predictors.

163 For regression models, this is determined by the equation: $A I C=n * \ln \left(\frac{R S S}{n}\right)+2 * K$ where $\mathrm{n}$ is

164 the number of observations, $\mathrm{K}$ is the number of predictors, and RSS is the residual sums of

165 squares. As with the paired t-test analyses, we developed two sets of regression models for each

$166 \%$ reduction response variable; one for reductions based off measured observations alone, and

167 one for reductions based off modeled and measured observations combined. We report the

168 proportion of variance explained as $\mathrm{R}^{2}$ for models with one predictor variable and as adjusted $\mathrm{R}^{2}$

169 for models with more than one variable.

170 3. Results

1713.1 Literature review

172 Our literature review initially resulted in 45 studies investigating a variety of topics

173 related to artificial drainage. A number of reasons led to excluding various studies from our

174 review including: the response variable tested was not of interest (e.g., crop yields); DWM +

175 subirrigation was the only drainage treatment tested; or drainage management occurred in open

176 ditches rather than subsurface tiles. After excluding research not suited for this review, we ended

177 up with 17 measured field studies that document the effectiveness of DWM to reduce nutrient

178 loading and drainage outflow from farm fields across a range of geographic regions (Table A.1).

179 For example, annual reductions of nitrate $\left(\mathrm{NO}_{3} \mathrm{~N}\right)$ and flow within managed drain tiles both 
ranged from 60-95\% in southern Sweden (Wesstrom and Messing 2007), while 62-96\% and 41-

$18195 \%$ reductions in tile $\mathrm{NO}_{3}{ }^{-} \mathrm{N}$ and tile flow were observed during two growing-seasons in

182 Ontario, Canada (Lalonde et al. 1996). In the Midwestern region of the U.S., average reductions

183 of $\mathrm{NO}_{3}{ }^{-} \mathrm{N}$ and flow from tiles were $36 \%$ and $37 \%$ in Iowa (Helmers et al. 2012) and $45 \%$ and

$18440 \%$ in Ohio (Fausey 2005). Cooke and Verma (2012) observed flow reductions of 35-96\% and

$185 \mathrm{NO}_{3}{ }^{-} \mathrm{N}$ reductions of 37-79\% in Illinois. Various versions of DRAINMOD (Skaggs 1978) and

186 the Root Zone Water Quality Model (RZWQM; Hanson et al. 1998) were used in the 11

187 modeling studies presented in our synthesis, with the majority utilizing DRAINMOD (i.e., 8

188 studies). Thorp et al. (2008) used a hybrid version of RZWQM combined with elements from

189 the Decision Support System for Agrotechnology Transfer (DSSAT; Jones et al. 2003) to

190 simulate the long-term performance of DWM across much of the midwestern United States. The

191 geographic range of the remaining simulations included in our paper also occurred in states

192 across the Midwest including Indiana (e.g., Ale et al. 2009; 2010; 2012a; 2012b), Iowa (e.g.,

193 Fang et al. 2012; Ma et al. 2007; Singh et al. 2007), and Minnesota (e.g., Luo et al. 2010). North

194 Carolina was the only non-midwestern state represented in the modeling studies obtained for our

195 review (e.g., Breve et al. 1998).

Relative to nitrogen, little research has occurred on the effectiveness of DWM to reduce

197 phosphorus loads (Figure 1), although the current research is promising. For example, Wesstrom

198 and Messing (2007) found total phosphorus load reductions of 56-95\% in managed compared to

199 free flowing drain tiles in southern Sweden. Williams et al. (2015) observed annual dissolved P

200 load reductions from 40-68\% in managed drains of Ohio. Further, Feser et al. (2010) found

201 evidence of $50 \%$ and $63 \%$ reductions of total and ortho-phosphorus loads respectively in

202 managed drain tiles of Minnesota. 
The reporting of potentially influential factors was highly variable across all studies

204 reviewed (Table 2). For example, greater than $90 \%$ of studies included information on drainage

205 components that have been well-studied in the tile drain literature (e.g., drain spacing, drain

206 depth). To contrast, we found relatively lesser rates (i.e., $30 \%-60 \%$ ) in reporting of some

207 potential predictors important to field hydrology (e.g., restrictive layer depth, precipitation

208 during the study). Surprisingly low rates $(<50 \%)$ were observed in other predictors that are

209 known to be important influences on nutrient characteristics (e.g., fertilizer application method

210 and timing) (Johnston and Bruulsema 2014).

\section{3.2. Overall performance of using DWM}

\section{3.2.1. Tile drainage and surface runoff volumes}

213 Drainage water management reduced tile flow by $46.3 \%(+/-10 \%)$ relative to free

214 drainage when considering all measured data (p-value $<0.001$; Table 3). For measured and

215 modeled data together, tile flow reductions were strikingly similar averaging $46.6 \%(+/-6 \%)$ less

216 flow than free drainage (p-value $<0.001$; Table 4). Surface runoff was 32.5\% (+/- 37\%) greater

217 under DWM than free drainage for measured observations $(n=12)$, but this difference was not

218 statistically significant $(\mathrm{p}$-value $=0.08$; Table 3 ). For measured and modeled observations

219 together $(\mathrm{n}=82)$, average surface runoff increased by $153.6 \%(+/-32 \%)$ with DWM and this

220 difference was highly significant statistically (p-value $<0.001$; Table 4). Tile discharge was

221 reduced by $43.8 \%(+/-14 \%)$ and $54.3 \%(+/-25 \%)$ when considering measured data that was

222 partitioned between growing and non-growing seasons respectively (Figure 2a; both p-values <

$2230.001)$.

224 3.2.2. Nitrate-nitrogen loads in tile drainage and surface runoff 
226 through subsurface drain tiles, with an average reduction of $47.8 \%(+/-12 \%)$ (p-value $<0.001$;

227 Table 3). Including modeled observations resulted in similar results, with $\mathrm{DWM}$ reducing $\mathrm{NO}_{3}{ }^{-}$

$228 \mathrm{~N}$ losses by $44.8 \%(+/-5 \%)$ from tiles (p-value < 0.001; Table 4). Measured $\mathrm{NO}_{3}{ }^{-} \mathrm{N}$ loads

$229(\mathrm{n}=10)$ in surface runoff were not different with DWM (p-value $=0.67$; Table 3$).$ The inclusion

230 of modeled observations $(n=83)$ into comparisons of $\mathrm{NO}_{3}{ }^{-} \mathrm{N}$ lost in surface runoff resulted in a

$23163.9 \%(+/-29 \%)$ increase with DWM (p < 0.001; Table 4). Tile $\mathrm{NO}_{3}{ }^{-} \mathrm{N}$ was reduced by $57.5 \%$

$232(+/-28 \%)$ and $67.4 \%(+/-24 \%)$ when comparing measured data that was partitioned between

233 growing and non-growing seasons respectively (Figure $2 \mathrm{~b}$; both p-values $<0.001$ ).

\section{3.2.3. Total and dissolved reactive phosphorus loads in tile drainage}

235 Drainage water management was also effective in reducing phosphorus loads being 236 exported through drain tiles (Figure 3). Total phosphorus lost through managed drains was

237 reduced $(\mathrm{p}$-value $=0.004)$ by $55.0 \%(+/-14.9 \%)$ while dissolved reactive phosphorus loads were 238 reduced $(\mathrm{p}$-value $=0.06)$ by $56.7 \%(+/-26.4 \%)($ Table 3$)$.

2393.3 Associating site specific landscape and farm management practices to percent reductions

$240 \quad$ 3.3.1 Tile drainage and surface runoff volumes

241 The $\%$ reduction of tile discharge was related to three farm and tile drain management

242 variables. Greater relative reductions in tile discharge were associated with narrower drain 243 spacing, deeper drain depths, and when tiles were managed during the non-growing season.

244 Additionally, this model explained a low to moderate amount of variation ( $\mathrm{p}$-value $=0.001, \mathrm{R}^{2}$

$245(\operatorname{adj})=0.23$; Table 5). When considering measured and modeled observations together only one 
246 drain management variable, drain depth, was positively associated with \% reduction of tile

247 discharge and explained a low amount of variation ( $\mathrm{p}$-value $=0.04, \mathrm{R}^{2}=0.04$; Table 6 ).

248 No associations were identified between predictor variables and \% reduction of surface

249 runoff when considering only measured observations (Table 5). When both measured and

250 modeled observations were considered, \% reduction of surface runoff was associated with one

251 site specific landscape and three farm and tile drain management variables. Regional

252 precipitation and drain depth were both negatively related, while outlet depth during the growing

253 season and outlet depth during the non-growing season were both positively related. A moderate

254 amount of variation was explained with this model ( $\mathrm{p}$-value $<0.001, \mathrm{R}^{2}(\operatorname{adj})=0.35$; Table 6 ).

\subsubsection{Nitrate-nitrogen loads in tile drainage and surface runoff}

The $\%$ reduction of $\mathrm{NO}_{3}{ }^{-} \mathrm{N}$ in tile drainage water was associated with one predictor

257 variable, considering measured observations only; fertilizer application rate had a negative

258 association with \% reduction of $\mathrm{NO}_{3}{ }^{-} \mathrm{N}$ lost in tile discharge (Figure 4). A low amount of

259 variation was explained in this model ( $\mathrm{p}$-value $=0.03, \mathrm{R}^{2}=0.14$; Table 5). Considering

260 measured and modeled observations together, $\%$ reduction of $\mathrm{NO}_{3}{ }^{-} \mathrm{N}$ in drain tiles was related to

261 four farm and tile drain management predictor variables. Growing season DWM, drain spacing

262 and fertilizer application rate were all negatively associated (Figures 5a-c), while drain depth was

263 positively related to the $\%$ reduction of $\mathrm{NO}_{3}{ }^{-} \mathrm{N}$ within drain tiles (Figure $5 \mathrm{~d}$ ). This model

264 explained a moderate amount of variation $\left(p-v a l u e<0.001, R^{2}(\operatorname{adj})=0.28\right.$; Table 6$)$.

265 No relationships were evident between predictor variables and \% reduction of $\mathrm{NO}_{3}{ }^{-} \mathrm{N}$ in

266 surface runoff when considering only measured observations (Table 5). When considering both

267 measured and modeled observations, one farm and tile drain management predictor variable was 
268 related; outlet depth during the non-growing season had a positive association with \% reduction

269 of $\mathrm{NO}_{3}{ }^{-} \mathrm{N}$ loads in surface runoff. This model explained a moderate amount of variation (p-value

$270<0.001, \mathrm{R}^{2}=0.25 ;$ Table 6).

$271 \quad$ 3.3.3 Total and dissolved reactive phosphorus loads in tile drainage

272 The $\%$ reduction of dissolved reactive phosphorus was unrelated to any predictor

273 variables used in this analysis (Table 5). We did however relate \% reduction of total phosphorus

274 loads in drain tiles with two farm and tile drain management predictor variables; drain spacing

275 and fertilizer application rate, and explained variation was high at $R^{2}(\operatorname{adj})=0.73(p-v a l u e=$

276 0.004; Table 5). Percent reductions were greater with more narrowly spaced drains, and when

277 lower fertilizer application rates were applied.

278 4. Discussion

279 4.1 Literature review

280 The use of DWM to reduce losses of water and nutrients is not without limitations. A 281 major consideration is that DWM implementation is generally restricted to flat areas (slopes < $2820.5 \%$ ) or where drainage systems have been installed on the contour so that larger areas can be 283 effectively managed by an individual structure (Frankenberger et al. 2006). All reported slopes in 284 this review were less than 1\% (e.g., Jaynes 2012, Lalonde et al. 1996, Williams et al. 2015).

285 Drainage water management also requires a tile drainage system to be available for management, 286 and is most effective where a pattern drainage system exists or is planned (Cooke et al. 2005;

287 Frankenberger et al. 2006). 
The reporting of potentially important predictors was highly variable across all studies

289 reviewed. Consideration of missing data while using traditional analytical techniques (e.g.,

290 multiple regressions) can be problematic; a challenge similarly noted in a previous DWM review

291 (Amenumey et al. 2009). Skaggs (2016) proposed that drainage research studies should report

292 three standard parameters that characterize the system, which he called the Kirkham Coefficient,

293 drainage intensity, and drainage coefficient. Including these three coefficients in future studies

294 will increase robustness of future comparisons and synthesis. We encourage researchers to report

295 these and as many potentially important factors as possible in their methods or in supplemental

296 materials to allow the reader to investigate potential influences from a suite of important factors.

297 For example, while different fertilizer types, application methods and timing vary in their

298 nutrient use-efficiencies, mobility, and subsequent losses (e.g., Ladha et al. 2005), $\leq 50 \%$ of the

299 studies reviewed reported sufficient detail regarding these variables. So, we were unable to test

300 potential influences from these predictors given our statistical methods.

Less focus has been placed on investigating the role drain tiles play in $\mathrm{P}$ lost from farms 302 compared to $\mathrm{N}$ loss as drain tiles were historically considered a minor factor in $\mathrm{P}$ movement

303 (Baker et al. 1975). While recent efforts have illustrated the importance of tile drainage in P

304 transport (King et al. 2015, Kleinman et al. 2015), the literature is lacking on the effectiveness of

305 DWM to reduce P lost through both subsurface tiles and surface runoff. As there is a paucity of

306 research focused on the effects of DWM on P lost in these pathways, there are additionally few

307 studies on the effectiveness of DWM in altering the movement of water and nutrients in various

308 other pathways including preferential flow, lateral flow, biological uptake, and groundwater

309 recharge (Skaggs et al. 2012).

$310 \quad 4.2$ Hydrology 
312 climates and farm management strategies has long been measured and reported in the literature

313 (Evans et al. 1989, Fausey 2005, Gilliam et al. 1979, Helmers et al. 2012, Lalonde et al. 1996).

314 Empirical research on the influence of DWM on surface runoff has received far less attention as

315 illustrated by our small sample size and insignificant results from t-tests using measured data

316 alone.

The consistency in tile discharge results between measured, and measured and modeled

318 evaluations combined provides strong evidence that modelling of tile discharge is consistent with

319 the empirically measured studies. The inconsistency of results regarding surface runoff volumes

320 could be a result of various factors. First, our synthesis considers data from a number of tile

321 management strategies that have occurred in a range of geographies having a variety of physical

322 soil properties that influence surface runoff (e.g., hydraulic conductivity, water holding

323 capacity). Additionally, there is little empirical research actually measuring surface runoff due

324 to difficulties in measuring water lost through this pathway, so somewhat variable responses due

325 to DWM is not necessarily unexpected. Future research should explicitly quantify surface runoff

326 responses to DWM and be sure to include information about site specific soil properties (e.g.,

327 soil type and texture) to help clarify the circumstances where DWM may increase surface runoff.

328 What is clear is that regardless of whether DWM leads to increased surface runoff, any increase

329 is likely, at least an order of magnitude smaller than the reduction of flow through drain tiles (see

330 Mean difference from Tables 3 \& 4). This supports the notion that DWM is an effective

331 agricultural conservation practice for reducing discharge of water from farm fields.

We identified non-growing season DWM as having a positive influence on the $\%$

333 reduction of tile discharge when analyzing both measured and modeled data. This result is 
334 supported by our comparison of growing and non-growing reductions separately as a greater \%

335 reduction (and raw difference) was observed for non-growing season than growing season data

336 (Figure 2a). This is not surprising as a substantial amount of agricultural runoff can occur during

337 the non-growing season (Stuntebeck et al. 2011) when snow melts and spring rains tend to be

338 frequent. So, more water flowing through drain tiles during the non-growing season should

339 generally provide a greater opportunity to reduce discharge through managed tile drains relative

340 to free draining tiles. As this is also a period when crop production is typically not possible, the

341 outlet depth can be held closer to the soil surface to more aggressively manage the drainage

342 water with little to no risk of negatively influencing crop yields (Skaggs et al. 2012).

343 Wider spaced drains were associated with lower $\%$ reductions in tile discharge while

344 deeper drains were associated with greater reductions using both measured and modeled

345 observations. Both are major components of any subsurface drainage system and in part rely on

346 natural factors such as climate and soil characteristics to determine the proper design. Shallower

347 drain depths have been shown to be an effective means of reducing tile discharge in fields that

348 are not managed with DWM structure (Sands et al. 2008), while wide compared to narrow drain

349 spacing additionally result in less intensive drainage (Kladivko et al. 2004). Our results (i.e.,

350 whether using only measured or measured and modeled data) suggest that under DWM, deeper

351 and/or narrower drain spacing provides more opportunity to reduce tile discharge relative to free

352 flowing tiles. This is plausible as both deep tiles and narrow tile spacing more intensively drain

353 the soil in unmanaged systems. Therefore, managing deep vs. shallow or narrow vs. wide drains

354 should result in larger volumes of water being held back and provide greater reductions, given

355 the water table is not flowing over the DWM structure flashboards for extended periods of time. 
357 climates with higher mean annual precipitation (and presumably wetter seasons) will result in

358 increased surface runoff compared to less wet climates or seasons. The occurrence of surface

359 runoff depends on various factors, including rainfall intensity and antecedent soil moisture (Kim

360 and Lee 2008) with overland flow more likely to occur on previously saturated soils that receive

361 intense rainfall. The use of DWM potentially keeps the soil more saturated (Helmers et al. 2012)

362 so the use of this practice in wetter climates or seasons potentially increases the chance of

363 surface runoff. The outlet depth (i.e., from the soil surface) during both the growing and non-

364 growing season showed a positive relationship with \% reduction of surface runoff. This suggests

365 that surface runoff is reduced with a deeper outlet depth. A lower water table should provide

366 more soil space available for infiltration of precipitation and a reduced risk of surface runoff to

367 occur.

368 4.3. Nutrient loads

369 Considerable attention within the literature has been focused on measuring the influence 370 of $\mathrm{DWM}$ on $\mathrm{NO}_{3}{ }^{-} \mathrm{N}$ lost through drain tiles, and results have illustrated considerable reductions

371 (Drury et al. 2009, Tan et al. 1998, Wesstrom and Messing 2007, Williams et al. 2015).

372 Consistency between measured and modeled tile $\mathrm{NO}_{3}{ }^{-} \mathrm{N}$ responses to DWM further illustrate the

373 potential of DWM to reduce $\mathrm{NO}_{3}{ }^{-} \mathrm{N}$ loading, and emphasizes the consistency of field-scale

374 simulations to predict N loss for both drain management treatments. Substantially greater

375 reductions in tile $\mathrm{NO}_{3}{ }^{-} \mathrm{N}$ were additionally observed during the non-growing season compared to

376 the growing season, likely linked to greater reductions in tile discharge (Figures $2 \mathrm{a} \& 2 \mathrm{~b}$ ).

377 Similar to hydrologic comparisons, the small sample size and range of climatic and physical soil

378 characteristics likely resulted in notably variable results for increased $\mathrm{NO}_{3}{ }^{-} \mathrm{N}$ loads in surface 
runoff. This highlights a need for more research to be focused on surface runoff characteristics to

380 help clarify the specific site parameters that might lead to increased nutrient loading within

381 surface runoff when implementing DWM. Regardless, our results suggest that DWM is an

382 effective conservation practice for reducing $\mathrm{NO}_{3}{ }^{-} \mathrm{N}$ loads exported from farm fields as any

383 potential increase in surface runoff loads due to DWM are overshadowed by the reduction of

$384 \mathrm{NO}_{3}{ }^{-} \mathrm{N}$ being lost through subsurface drain tiles (see Mean difference from Tables $3 \& 4$ ).

A negative association between fertilizer application rate and \% reduction of $\mathrm{NO}_{3}{ }^{-} \mathrm{N}$ loads from drain tiles was identified whether using measured only, or measured and modeled data.

387 Greater application rates lead to greater proportions of $\mathrm{NO}_{3}{ }^{-} \mathrm{N}$ lost from farm fields. If nutrient 388 application exceeds instead of simply meeting crop requirements, it is expected that a greater 389 proportion will be lost whether managed under DWM or free draining. This concurs with

390 previous research on $\mathrm{NO}_{3}{ }^{-} \mathrm{N}$ lost in free drainage systems as the greatest fertilizer application rate 391 resulted in greater losses of $\mathrm{NO}_{3}{ }^{-} \mathrm{N}$ within drain tiles in Iowa compared to two lower application 392 rates (Jaynes et al. 2001). The negative relationship (i.e., when pooling measured and modeled 393 data) between $\%$ reduction of tile $\mathrm{NO}_{3}{ }^{-} \mathrm{N}$ loads with both drain spacing and growing season 394 DWM, and the positive relationship with drain depth is plausible as the reduction of $\mathrm{NO}_{3}{ }^{-} \mathrm{N}$ from 395 drain tiles from using DWM has typically resulted from reductions in tile flow rather than 396 reducing concentrations (Evans et al. 1989, Gilliam et al. 1979, Helmers et al. 2012, Lalonde et 397 al. 1996, Tan et al. 1998, Wesstrom and Messing 2007). While denitrification is often speculated 398 as being promoted by DWM (e.g., Lalonde et al. 1996), its role in reducing $\mathrm{NO}_{3}{ }^{-} \mathrm{N}$ lost through 399 tiles is typically secondary to reduced tile discharge (Wahba et al. 2001). This is partially 400 because the anaerobic conditions necessary to enhance denitrification are promoted to a greater 401 extent using DWM in the non-growing season compared to the growing season as outlets can be 
managed more aggressively, thus keeping more soil saturated for longer periods of time.

403 Temperatures are also cooler in the non-growing season, restricting the biological activity

404 necessary for denitrification to occur (e.g., Woli et al. 2010). This mismatch in suitable

405 denitrification conditions that come with implementing DWM have limited this mechanism as a

406 way to reduce $\mathrm{NO}_{3}{ }^{-} \mathrm{N}$ loads. As this influence of DWM has generally been consistent, drain

407 system parameters that increase or decrease relative reductions in tile flow should additionally

408 alter $\mathrm{NO}_{3}{ }^{-} \mathrm{N}$ loads from tiles.

Lower \% reduction in $\mathrm{NO}_{3}{ }^{-} \mathrm{N}$ (and flow) is more likely on fields with drains spaced wider

410 vs. narrower or drains installed shallower vs. deeper. Drainage intensity integrates these two

411 variables, along with effective saturated hydraulic conductivity of the profile and depth to

412 restrictive layer (Skaggs, 2016) and provides a parameter to consistently document this. Greater

413 relative reductions are possible when using DWM in fields with higher drainage intensity.

414 Similarly, the negative relationship with growing season DWM is likely because a substantial

415 amount of agricultural runoff occurs during the non-growing season. Comparing $\mathrm{NO}_{3}{ }^{-} \mathrm{N}$

416 partitioned between seasons illustrate that only managing tiles during the growing season will

417 generally result in lower relative reduction in tile $\mathrm{NO}_{3}{ }^{-} \mathrm{N}$ loads and flow than if drains were

418 managed during the non-growing season or year round (Figure 2b).

419 Just as deeper drains were positively associated with reductions in surface runoff volume,

420 a similar relationship was identified with $\mathrm{NO}_{3}{ }^{-} \mathrm{N}$ lost in surface runoff (i.e., analyzing measured

421 and modeled data together). Specifically, our results suggest that keeping the drainage outlet

422 deeper in the non-growing season will lead to less increase in $\mathrm{NO}_{3}{ }^{-} \mathrm{N}$ loads within surface runoff.

423 This is likely because more intense drainage leads to a lower water table, which also lowers the

424 risk of surface runoff and associated nutrient losses to occur. 
While there is promising evidence that DWM can be an effective strategy for mitigating

426 phosphorus losses from agricultural landscapes, we only had 12 observations from 3 studies for

427 total phosphorus and 10 observations from 4 studies for dissolved reactive phosphorus.

428 Analyzing these few data resulted in relatively large standard errors and $90 \%$ confidence

429 intervals for the mean difference of $\mathrm{P}$ response variables. This gap needs to be addressed with

430 future researchers placing more emphasis on assessing the effects of DWM on P exported from

431 farm fields. Further, the only study we found measuring the influence of DWM on P lost within

432 surface runoff also included sub-irrigation (Tan and Zhang 2011), so the effect of DWM was not

433 possible to determine given our methods. Regardless, the authors of this study found increased

434 concentrations of various forms of phosphorus in surface runoff and tile discharge due to DWM

435 and sub-irrigation. These results demonstrate a need to more thoroughly understand P dynamics

436 for all pathways under DWM including not only surface runoff, but also preferential flow, lateral

437 flow, deep groundwater recharge and biological uptake.

The altered hydrology may also extend the time that the water table is interacting with the

439 topsoil which tends to be rich in phosphorus, especially in agricultural landscapes with a long

440 history of annual fertilizer applications (Mardamootoo et al. 2010). Additionally, elevated water

441 tables for prolonged periods may promote anoxic conditions suitable for reduction of phosphorus

442 bound minerals like aluminum and especially iron (Yaghi and Hartikainen 2013). Both have the

443 potential to increase the mobility of biologically available forms of phosphorus.

444 Greater relative reductions of total phosphorus loads in drain tiles are possible in fields

445 with lower fertilizer application rates and fields with narrower spaced drain tiles. These results

446 appear to be opposite sides of the same coin; one side suggests that over-application of fertilizer

447 will reduce the effectiveness of DWM to mitigate P losses, potentially due to the management 
448 system not being able to keep up with the amount of fertilizer being applied. The other side of

449 this coin implies that more narrowly spaced tiles provide more intense drainage and greater

450 nutrient export (King et al. 2015). This would allow for more water (and total phosphorus) to be

451 held back by raising tile outlets than in a field with wider spaced tiles.

\section{5. Conclusions}

$453 \quad 5.1$ Review summary

This review illustrates that DWM is an effective conservation practice for reducing

455 drainage outflow and $\mathrm{NO}_{3}{ }^{-} \mathrm{N}$ loads to receiving water-bodies in a variety of agricultural

456 landscapes. The greatest potential for DWM to reduce discharge of water and $\mathrm{NO}_{3}{ }^{-} \mathrm{N}$ from tiles is

457 during the non-growing season when outlets can be managed most aggressively, and is also

458 when most drain flow often occurs. Reductions in tile $\mathrm{NO}_{3}{ }^{-} \mathrm{N}$ are mainly due to reduced tile

459 discharge rather than enhanced denitrification. While intensively managed drain tiles may

460 increase $\mathrm{NO}_{3}{ }^{-} \mathrm{N}$ lost with surface runoff, concentrations are much lower in surface runoff and

461 there is little evidence that this increase would overshadow the reductions observed in drain tiles.

\subsection{Limitations and future research suggestions}

Drainage water management appears to be an effective strategy for reducing $\mathrm{P}$ losses

464 through drain tiles. However, there is a paucity of research currently available and this needs

465 further investigation. For example, while the \% reductions presented for $\mathrm{P}$ are substantial, the 466 actual loads they are based off are quite low, so the effectiveness of DWM to reduce greater P

467 loads could be a topic of future research. Key knowledge gaps on the impact of DWM to affect 468 other flow pathways, particularly surface runoff and associated nutrients (especially phosphorus)

469 lost through this pathway need further attention in the literature. We did not have the ability to 
470 assess relationships between DWM and preferential flow paths, which can be a major pathway

471 for $\mathrm{P}$ to reach drain tiles in unmanaged systems (King et al. 2015). We additionally did not

472 specifically assess any potential effects of crop type on DWM effectiveness, or influences of

473 DWM on shallow groundwater flow or deep groundwater recharge; all of which warrant further

474 investigation in future studies. Further, we suggest that future research continue to quantify how

475 DWM in combination with other agricultural practices (e.g., sub-irrigation) enhance or inhibit

476 the effectiveness of DWM to reduce drainage water discharge and nutrient loads from farm fields

477 relative to traditional free draining tiles. Finally, continued investigation and comparisons of the

478 potential impact of DWM on hydrology and water quality via large-scale watershed modeling

479 efforts can help save time and money by prioritizing those areas that will benefit most from

480 DWM implementation. So, modeling efforts should continue to provide insight on adoption of

481 this practice in highly agricultural landscapes and the resulting impacts at various spatial scales. 


\section{Acknowledgments}

483 The authors wish to thank the University of Michigan Water Center for their financial support of 484 this project. We also wish to thank Dr. Jordi Moya-Laraño from the Arid Zone Experimental 485 Station for providing information regarding the use of partial regression plots, as well as Nancy

486 Sammons at the USDA-ARS, Grassland Soil and Water Research Laboratory and Sara Leavitt 487 from The Nature Conservancy for extensive logistical support throughout the process of 488 completing this research. Chris May and Kim Hall from The Nature Conservancy, and two

489 anonymous reviewers also deserve thanks as they provided very helpful insight on earlier 490 versions of this manuscript. 
492 Adeuya, R., Utt, N., Frankenberger, J., Bowling, L., Kladviko, E., Brouder, S., Carter, B., 2012.

493 Impacts of drainage water management on subsurface drain flow, nitrate concentration, and

494 nitrate loads in Indiana. J. Soil Water Conserv. 67, 474-484.

495 Akaike, H. 1973. Information theory and an extension of the maximum likelihood principle, in:

496 Petrov, B.N., Csáki, F., 2nd International Symposium on Information Theory, Tsahkadsor, 497 Armenia, USSR, September 2-8, 1971, Budapest: Akadémiai Kiadó, p. 267-281.

498 Ale, S., Bowling, L.C., Brouder, S.M., Frankenberger, J.R., Youssef, M.A., 2009. Simulated

499 effect of drainage water management operational strategy on hydrology and crop yield for

500 Drummer soil in the Midwestern United States. Agric. Water Manage. 96, 653-665.

501 Ale, S., Bowling, L.C., Frankenberger, J.R., Brouder, S.M., Kladviko, E.J., 2010. Climate

502 variability and drain spacing influence on drainage water management system operation. Vadose

503 Zone J. 9, 43-52.

504 Ale, S., Bowling, L.C., Owens, P.R., Brouder, S.M., Frankenberger, J.R., 2012a. Development

505 and application of a distributed modeling approach to assess the watershed-scale impact of

506 drainage water management. Agric. Water Manage. 107, 23-33.

507 Ale, S., Bowling, L.C., Youssef, M.A., Brouder, S.M., 2012b. Evaluation of simulated strategies

508 for reducing nitrate-nitrogen losses through subsurface drainage systems. J. Environ. Qual. 41, $509 \quad 217-228$. 
510 Amenumey, S., Sands, G., Wilson, B., Mulla, D., Nieber, J., and Swenson, J., 2009. Meta-

511 analysis as a statistical tool for evaluating the hydrologic effects of water table management.

512 ASABE Paper No. 096152. St. Joseph, MI. DOI:10.13031/2013.27066.

513 Baker, J.L., Campbell, K.L., Johnson, H.P., Hanway, J.J., 1975. Nitrate, phosphorus, and sulfate

514 in subsurface drainage water. J. Environ. Qual. 4, 406-412.

515 Blann, K.L., Anderson, J.L., Sands, G.R., Vondracek, B., 2009. Effects of agricultural drainage

516 on aquatic ecosystems: A review. Crit. Rev. Env. Sci. Tec. 39, 909-1001.

517 Breitburg, D.L., Hondorp, D.W., Davias, L.A., Diaz, R.J., 2009. Hypoxia, nitrogen, and

518 fisheries: integrating effects across local and global landscapes. Ann. Rev. Mar. Sci. 1, 329-349.

519 Breve, M.A., Skaggs, R.W., Gilliam, J.W., Parsons, J.E., Mohammad, A.T., Chescheir, G.M., 520 Evans, R.O., 1997. Field testing of Drainmod-N. T. ASAE 40, 1077-1085.

521 Breve, M.A., Skaggs, R.W., Parsons, J.E., Gilliam, J.W., 1998. Using the DRAINMOD-N model

522 to study effects of drainage system design and management on crop productivity, profitability

523 and $\mathrm{NO}_{3}{ }^{-} \mathrm{N}$ losses in drainage water. Agric. Water Manage. 35, 227-243.

524 Chatterjee, S., A.S. Hadi, and B. Price. 2000. Regression analysis by example. John Wiley and 525 Sons, New York, New York, USA.

526 Cooke, R.A., G.R. Sands, and L.C. Brown. 2005. Drainage water management: A practice for 527 reducing nitrate loads from subsurface drainage systems. pp 27-34. Proceedings of the Gulf 528 hypoxia and local water quality concerns workshop. Sept. 26-28, Ames, Iowa.

529 Cooke, R., Verma, S., 2012. Performance of drainage water management systems in Illinois. J. 530 Soil Water Conserv. 67, 453-464. 
531 David, M.B., Drinkwater, L.E., McIsaac, G.F., 2010. Sources of nitrate yields in the Mississippi

532 River Basin. J. Environ. Qual. 39, 1657-1667.

533 Drury, C.F., Tan, C.S., Reynolds, W.D., Welacky, T.W., Oloya, T.O., Gaynor, J.D., 2009.

534 Managing tile drainage, subirrigation, and nitrogen fertilization to enhance crop yields and

535 reduce nitrate loss. J. Environ. Qual. 38, 1193-1204.

536 Evans, R.O., Gilliam, J.W., Skaggs, R.W., 1989. Effects of agricultural water table management

537 on drainage water quality. Report 237, Water Resources Research Institute of the University of

538 North Carolina. Raleigh, NC: North Carolina State University.

539 Fang, Q.X., Malone, R.W., Ma, L., Jaynes, D.B., Thorp, K.R., Green, T.R., Ahuja, L.R., 2012.

540 Modeling the effects of controlled drainage, $\mathrm{N}$ rate and weather on nitrate loss to subsurface

541 drainage. Agric. Water Manage. 103, 150-161.

542 Fausey, N.R., 2005. Drainage management for humid regions. International Agricultural

543 Engineering Journal 14, 209-214.

544 Fausey, N.R., Brown, L.C., Belcher, H.W., Kanwar, R.S., 1995. Drainage and water quality in

545 Great Lakes and Cornbelt states. J. Irrig. Drain. E. 121, 283-288.

546 Feser, S.E., Strock, J.S., Sands, G.R., Birr, A.S., 2010. Controlled drainage to improve edge-of-

547 field water quality in southwest Minnesota, USA. XVIIth World Congress of the International

548 Commission of Agricultural and Biosystems Engineering. 13-17 June 2010. Quebec City,

549 Quebec, Canada. 
550 Frankenberger, J., Kladviko, E., Sands, G., Jaynes, D., Fausey, N., Helmers, M., Cooke, R.,

551 Strock, J., Nelson, K., Brown L., 2006. Drainage water management for the Midwest: Questions

552 and answers about drainage water management for the Midwest. Purdue Extension., pp. 8.

553 Gaynor, J.D., Tan, C.S., Drury, C.F., Welacky, T.W., Ng, H.Y., Reynolds, W.D., 2002. Runoff

554 and drainage losses of atrazine, metribuzin, and metolachlor in three water management systems.

555 J. Environ. Qual. 31, 300-308.

556 Gilliam, J.W., Skaggs, R.W., Weed, S.B., 1979. Drainage control to diminish nitrate loss from

557 agricultural fields. J. Environ. Qual. 8, 137-142.

558 Hair, J., W.C. Black, B.J. Babin, and R.E. Anderson. 2010. Multivariate data analysis, $7^{\text {th }}$ ed.

559 Upper Saddle River, New Jersey: Pearson Education International.

560 Hanson, J.D., L.R. Ahuja, M.D. Shaffer, K.W. Rojas, D.G. DeCoursey, H. Farahani, and K.

561 Johnson. 1998. RZWQM: Simulating the effects of management on water quality and crop

562 production. Agric. Syst. 57:161-195.Helmers, M., Christianson, R., Brenneman, G., Lockett, D.,

563 Pederson, C., 2012. Water table, drainage, and yield response to drainage water management in

564 southeast Iowa. J. Soil Water Conserv. 67, 495-501.

565 Jaynes, D.B., 2012. Changes in yield and nitrate losses from using drainage water management

566 in central Iowa, United States. J. Soil Water Conserv. 67, 485-494.

567 Jaynes, D.B., Colvin, T.S., Karlen, D.L., Cambardella, C.A., Meek, D.W., 2001. Nitrate loss in

568 subsurface drainage as affected by nitrogen fertilizer rate. J. Environ. Qual. 30, 1305-1314.

569 Johnston, A.M., Bruulsema, T.W., 2014. 4R Nutrient stewardship for improved nutrient use 570 efficiency. Procedia Engineering 83, 365-370. 
571 Jones, J.W., G. Hoogenboom, C.H. Porter, K.J. Boote, W.D. Batchelor, L.A. Hunt, P.W.

572 Wilkens, U. Singh, A.J. Gijsman, and J.T. Ritchie. 2003. The DSSAT cropping systems model.

573 Eur. J. Agron. 18:235-265.

574 Kim, N.W., Lee, J., 2008. Temporally weighted average curve number method for daily runoff

575 simulation. Hydrol. Process. 22, 4936-4948.

576 King, K.W., Williams, M.R., Macrae, M.L., Fausey, N.R., Frankenberger, J., Smith, D.R.,

577 Kleinman, P.J.A., Brown, L.C., 2015. Phosphorus transport in agricultural subsurface drainage:

578 A review. J. Environ. Qual. 44, 467-485.

579 Kladivko, E.J., Frankenberger, J.R., Jaynes, D.B., Meek, D.W., Jenkinson, B.J., Fausey, N.R., 580 2004. Nitrate leaching to subsurface drains as affected by drain spacing and changes in crop 581 production system. J. Environ. Qual. 33, 1803-1813.

582 Kleinman, P.J.A., Smith, D.R., Bolster, C.H., Easton, Z.M., 2015. Phosphorus fate, management, 583 and modeling in artificially drained systems. J. Environ. Qual. 44, 460-466.

584 Lalonde, V., Madramootoo, C.A., Trenholm, L., Broughton, R.S., 1996. Effects of controlled 585 drainage on nitrate concentrations in subsurface drain discharge. Agric. Water Manage. 29, 187586199.

587 Ludsin, S.A., Kershner, M.W., Blocksom, K.A., Knight, R.L., Stein, R.A., 2001. Life after death 588 in Lake Erie: nutrient controls drive fish species richness, rehabilitation. Ecol. Appl. 11, 731589746. 
590 Luo, W., Sands, G.R., Youssef, M., Strock, J.S., Song, I., Canelon, D., 2010. Modeling the 591 impact of alternative drainage practices in the northern Corn-belt with DRAINMOD-II. Agric.

592 Water Manage. 97, 389-398.

593 Ma, L., Malone, R.W., Heilman, P., Jaynes, D.B., Ahuja, L.R., Saseendran, S.A., Kanwar, R.S., 594 Ascough II, J.C., 2007. RZWQM simulated effects of crop rotation, tillage, and controlled 595 drainage on crop yield and nitrate-N loss in drain flow. Geoderma. 140, 260-271.

596 Mardamootoo, T., Kwong, K.F.N.K., Du Preez, C.C., 2010. History of phosphorus fertilizer 597 usage and its impact on the agronomic phosphorus status of sugarcane soils in Mauritius. Sugar 598 Tech. 12, 91-97.

599 Miltner, R. J., 2010. A method and rational for deriving nutrient criteria for small rivers and 600 streams in Ohio. Environ. Manage. 45, 842-855.

601 Nangia, V., Gowda, P.H., Mulla, D.J., Sands, G.R., 2008. Water quality modeling of fertilizer 602 management impacts on nitrate losses in tile drains at the field scale. J. Environ. Qual. 37, 296603307.

604 Pitts, D.J., Cooke, R., Terrio, P.J., 2004. Illinois drainage water management demonstration 605 project, in: Cooke, R. (Ed.), Drainage VIII Proceedings of the Eighth International Symposium, 606 21-24 March 2004 (Sacramento, California USA), Publication Date 21 March 2004. ASAE 607 Publication Number 701P0304, pp. 25-38.

608 Sands, G.R., Song, I., Busman, L.M., Hansen, B.J., 2008. The effects of subsurface drainage 609 depth and intensity on nitrate loads in the northern cornbelt. T. ASABE 51, 937-946. 
610 Sharpley, A.N., Chapra, S.C., Wedepohl, R., Sims, J.T., Daniel, T.C., Reddy, K.R., 1994.

611 Managing agricultural phosphorus for protection of surface waters: Issues and options. J.

612 Environ. Qual. 23, 437-451.

613 Singh, R., Helmers, M.J., Crumpton, W.G., Lemkie, D.W., 2007. Predicting effects of drainage

614 water management in Iowa's subsurface drained landscape. Agric. Water Manage. 92, 162-170.

615 Skaggs, R.W. 1978. A water management model for shallow water table soils. Technical Report

616 No. 134. Water Resources Research Institute of the University of North Carolina, Raleigh, N.C.

617 Skaggs, R.W., Nassehzadeh-Tabrizi, A., Foster, G.R., 1982. Subsurface drainage effects on

618 erosion. J. Soil Water Conserv. 37, 167-172.

619 Skaggs, R.W., Fausey, N.R., Evans, R.O., 2012. Drainage water management. J. Soil Water

620 Conserv. 67, 167A-172A.

621 Skaggs, R.W., 2016. Quantifying Subsurface Drainage Rates for Research Sites. In 2016 10th

622 International Drainage Symposium Conference, 6-9 September 2016, Minneapolis, Minnesota.

623 American Society of Agricultural and Biological Engineers. Paper Number 162493719. DOI:

624 10.13031/ids.20162493719

625 Smith, D.R., King, K.W., Williams, M.R., 2015. What is causing the harmful algal blooms in

626 Lake Erie? J. Soil Water Conserv. 70, 27A-29A.

627 Stuntebeck, T.D., Komiskey, M.J., Peppler, M.C., Owens, D.W., Frame, D.R., 2011.

628 Precipitation-runoff relations and water quality characteristics at edge-of-field stations,

629 Discovery Farms and Pioneer Farm, Wisconsin, 2003-8: U.S. Geological Survey Scientific

630 Investigations Report 2011-5008, 46 p., plus five appendixes. 
631 Tan, C.S., Drury, C.F., Soultani, M., van Wesenbeek, I.J., Ng, H.Y.F., Gaynor, J.D., Welacky,

632 T.W., 1998. Effects of controlled drainage and tillage on soil structure and tile drainage nitrate

633 loss at the field scale. Water Sci. Technol. 38, 103-110.

634 Thorp, K.R., Jaynes, D.B., Malone, R.W., 2008. Simulating the long-term performance of

635 drainage water management across the Midwestern United States. T. ASABE. 51, 961-976.

636 Wahba, M.A.S., El-Ganainy, M., Abdel-Dayem, M.S., Gobran, A.T.E.F., Kandil, H., 2001.

637 Controlled drainage effects on water quality under semi-arid conditions in the western delta of

638 Egypt. Irrig. Drain. 50, 295-308.

639 Weigel, B.M., Robertson, D.M., 2007. Identifying biotic integrity and water chemistry relations

640 in nonwadeable rivers of Wisconsin: towards the development of nutrient criteria. Environ.

641 Manage. 40, 691-708.

642 Wesstrom, I., Messing, I., 2007. Effects of controlled drainage on $\mathrm{N}$ and P losses and $\mathrm{N}$

643 dynamics in a loamy sand with spring crops. Agric. Water Manage. 87, 229-240.

644 Williams, M.R., King, K.W., Fausey, N.R., 2015. Drainage water management effects on tile

645 discharge and water quality. Agric. Water Manage. 148, 43-51.

646 Woli, K.P., David, M.B., Cooke, R.A., McIsaac, G.F., Mitchell, C.A., 2010. Nitrogen balance in

647 and export from agricultural fields associated with controlled drainage systems and denitrifying

648 bioreactors. Ecol. Eng. 1558-1566.

649 Yaghi, N., Hartikainen, H., 2013. Enhancement of phosphorus sorption onto light expanded clay 650 aggregates by means of aluminum and iron oxide coatings. Chemosphere. 93, 1879-1886. 
Table 1. Potentially important predictor variables identified in literature search.

\begin{tabular}{llll}
\hline & Site specific landscape & \multicolumn{2}{c}{ Farm and tile drain management } \\
\cline { 2 - 4 } Study setting & Site condition context & Farm practices & Tile management practices \\
\hline General location & Plot area & Crop type & Growing season DWM \\
Overall study period & Plot slope & Cover crops & Non-growing season DWM \\
Regional topography & Soil type & Herbicide application & Dates tiles are managed \\
Regional climate & Soil classification & Tillage practices & Drain diameter \\
Regional precipitation & Hydraulic conductivity & Nutrient application rate & Drain spacing \\
Regional temperature & Percent (\%) sand & Nutrient application method & Drain depth \\
Regional evapotranspiration & Percent (\%) silt & Nutrient application timing & Drain slope \\
Growing season & Percent (\%) clay & & Drainage coefficient \\
& Precipitation during the study & Growing season outlet depth \\
& Temperature during the study & Non-growing season outlet \\
& Evapotranspiration during study & & depth \\
& Water table depths during study & & \\
& Restrictive layer depth & &
\end{tabular}


Table 2. Potentially important predictor variables across all studies used in analyses organized by the rate (\% of papers) at which they were reported.

\begin{tabular}{|c|c|c|c|}
\hline$\leq 25 \%$ & $26 \%-50 \%$ & $51 \%-75 \%$ & $76 \%-100 \%$ \\
\hline Drain slope & Drain diameter & Percent (\%) sand ${ }^{\mathrm{a}}$ & Drain depth \\
\hline Drainage coefficient & Fertilizer application timing & Percent $(\%)$ silt $^{\mathrm{a}}$ & Drain spacing \\
\hline Evapotranspiration during the study & Fertilizer type & Percent $(\%)$ clay $^{\mathrm{a}}$ & Soil type \\
\hline Fertilizer application method & Growing season & Fertilizer application rate & Season outlets are managed ${ }^{\mathrm{b}}$ \\
\hline Herbicide application & Hydraulic conductivity & Precipitation during the study & Seasonal outlet depths ${ }^{b}$ \\
\hline Regional climate & Plot slope & Soil classification & Cover crops $^{c}$ \\
\hline Regional evapotranspiration & Restrictive layer depth & Dates tiles are managed & Crop type \\
\hline Regional topography & & & General location \\
\hline Temperature during the study & & & Overall study period \\
\hline \multirow[t]{4}{*}{ Water table depths during study } & & & Plot area \\
\hline & & & Regional precipitation $^{\mathrm{a}}$ \\
\hline & & & Regional temperature $^{a}$ \\
\hline & & & Tillage practices $^{\mathrm{c}}$ \\
\hline
\end{tabular}

${ }^{a}$ Efforts were taken to fill in data for these variables when not reported

${ }^{\mathrm{b}}$ Season and seasonal refers to growing season or non-growing season

${ }^{\mathrm{c}}$ If not reported, we assumed cover crops were not grown and tillage practices were conventional 
Table 3. Paired t-test results comparing all measured free drainage (FD) to drainage water management (DWM) observations for hydrology and nutrient response variables of interest. Growing and non-growing season data are pooled together.

\begin{tabular}{|c|c|c|c|c|c|c|c|c|}
\hline \multirow{2}{*}{$\begin{array}{l}\text { Response } \\
\text { variable }\end{array}$} & \multirow{2}{*}{$\begin{array}{l}\text { Mean } \% \\
\text { reduction }\end{array}$} & \multirow[b]{2}{*}{$n^{b}$} & \multirow[b]{2}{*}{ p-value } & \multirow{2}{*}{$\begin{array}{c}\text { Mean } \\
\text { difference }^{\mathrm{a}}\end{array}$} & \multicolumn{2}{|c|}{ Mean } & \multicolumn{2}{|c|}{$\begin{array}{l}95 \% \text { CI of mean } \\
\text { difference }^{c}\end{array}$} \\
\hline & & & & & FD & DWM & Lower & Upper \\
\hline Discharge & & & & & & $-\mathrm{mm}-$ & & \\
\hline Tile & 46.26 & 58 & $<0.001$ & 140.68 & 304.10 & 163.42 & 110.12 & 171.24 \\
\hline Surface & -32.48 & 12 & 0.08 & -27.58 & 84.92 & 112.50 & -59.29 & 4.12 \\
\hline Tile load & & & & & $\mathrm{k}$ & $\mathrm{ha}^{-1} \mathrm{yr}^{-}$ & & \\
\hline Nitrate-N & 47.82 & 56 & $<0.001$ & 13.53 & 28.29 & 14.76 & 10.12 & 16.94 \\
\hline $\mathrm{DRP}^{\mathrm{d}, \mathrm{e}}$ & 56.74 & 10 & 0.06 & 0.10 & 0.18 & 0.08 & 0.02 & 0.19 \\
\hline Total- $\mathrm{P}^{\mathrm{e}}$ & 54.97 & 12 & 0.004 & 0.07 & 0.13 & 0.06 & 0.04 & 0.10 \\
\hline Surface load & & & & & & & & \\
\hline Nitrate-N & -13.25 & 10 & 0.67 & -0.35 & 2.62 & 2.97 & -1.41 & 2.10 \\
\hline
\end{tabular}

${ }^{\mathrm{a}}$ Negative reduction and difference refers to an increase from FD to DWM

${ }^{b} \mathrm{n}$ refers to the number of paired observations used for comparison

${ }^{\mathrm{c}} \mathrm{CI}$ refers to confidence interval

${ }^{\mathrm{d}}$ DRP refers to dissolved reactive phosphorus

${ }^{\mathrm{e}} 90 \% \mathrm{CI}$ of the mean difference is presented for phosphorus response variables 
Table 4. Paired t-test results comparing measured and modeled free drainage (FD) to drainage water management (DWM) observations of hydrology and nutrient response variables of interest. Growing and non-growing season data are pooled together.

\begin{tabular}{|c|c|c|c|c|c|c|c|c|}
\hline \multirow{2}{*}{$\begin{array}{c}\text { Response } \\
\text { variable }\end{array}$} & \multirow{2}{*}{$\begin{array}{l}\text { Mean \% } \\
\text { reduction }\end{array}$} & \multirow[b]{2}{*}{$n^{\mathrm{b}}$} & \multirow[b]{2}{*}{$\mathrm{p}$-value } & \multirow{2}{*}{$\begin{array}{c}\text { Mean } \\
\text { difference }^{\mathrm{a}}\end{array}$} & \multicolumn{2}{|c|}{ Mean } & \multicolumn{2}{|c|}{$\begin{array}{l}\text { 95\% CI of mean } \\
\text { difference }\end{array}$} \\
\hline & & & & & FD & DWM & Lower & Upper \\
\hline Discharge & & & & & & $\mathrm{mm}$ & & \\
\hline Tile & 46.57 & 131 & $<0.001$ & 128.90 & 276.78 & 147.88 & 112.32 & 145.48 \\
\hline Surface & -153.59 & 82 & $<0.001$ & -59.73 & 38.89 & 98.62 & -72.34 & -47.13 \\
\hline Nitrate-N load & & & & & $\mathrm{k}$ & $\mathrm{ha}^{-1} \mathrm{yr}^{-1}$ & & \\
\hline Tile & 44.84 & 205 & $<0.001$ & 11.61 & 25.89 & 14.28 & 10.23 & 12.98 \\
\hline Surface & -63.88 & 83 & $<0.001$ & -0.62 & 0.97 & 1.60 & -0.91 & -0.34 \\
\hline
\end{tabular}

${ }^{\mathrm{a}}$ Negative reduction and difference refers to an increase from FD to DWM

${ }^{b} \mathrm{n}$ refers to the number of paired observations used for comparison

${ }^{\mathrm{c}} \mathrm{CI}$ refers to confidence interval 
Table 5. Multiple linear regression results using only measured observations to identify relationships between the percent (\%) reduction of response variables of interest with site specific landscape and farm and tile drain management predictor variables.

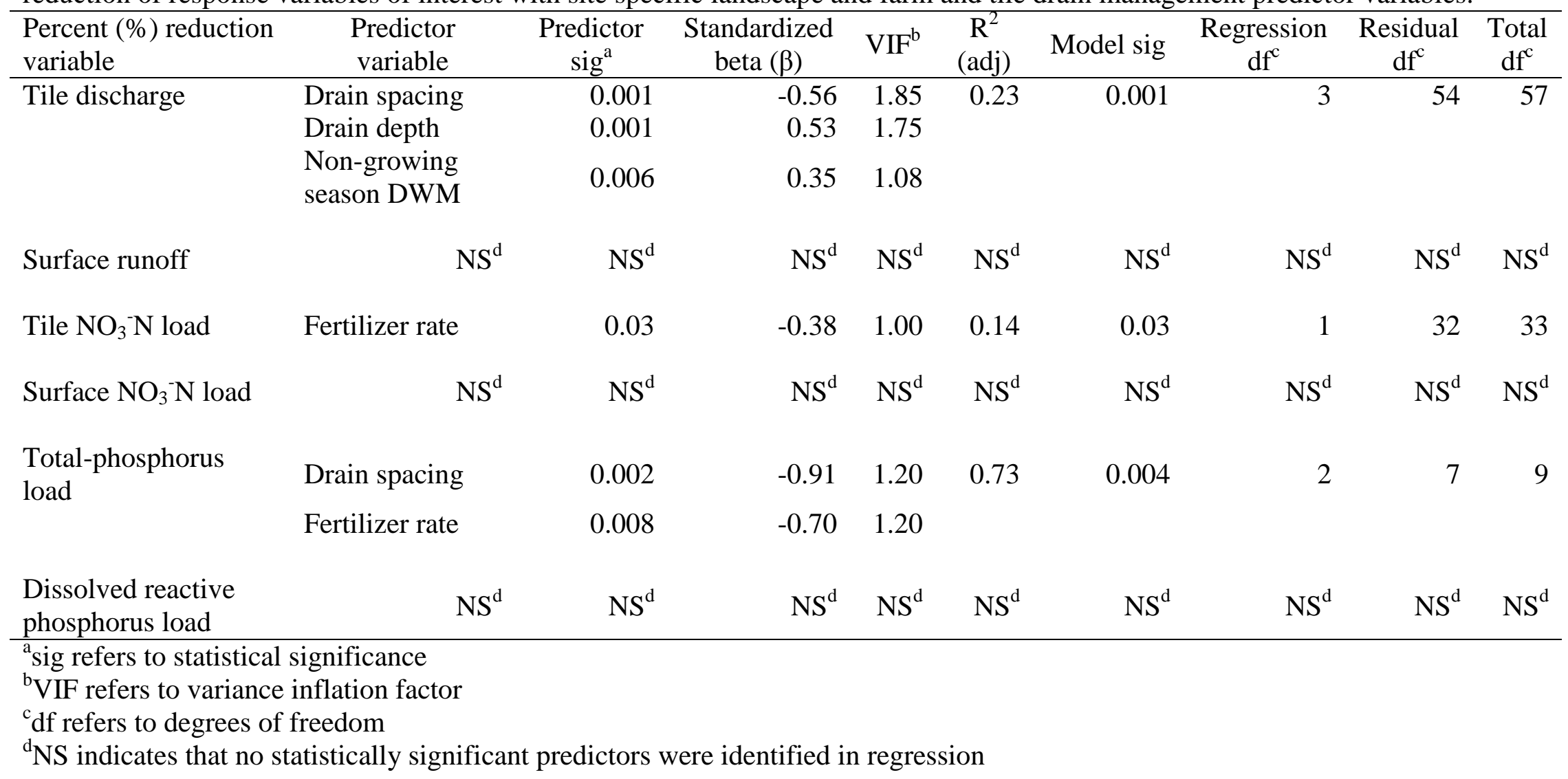


Table 6. Multiple linear regression results using measured and modeled observations to identify relationships between the percent (\%) reduction of response variables of interest with site specific landscape and farm and tile drain management predictor variables.

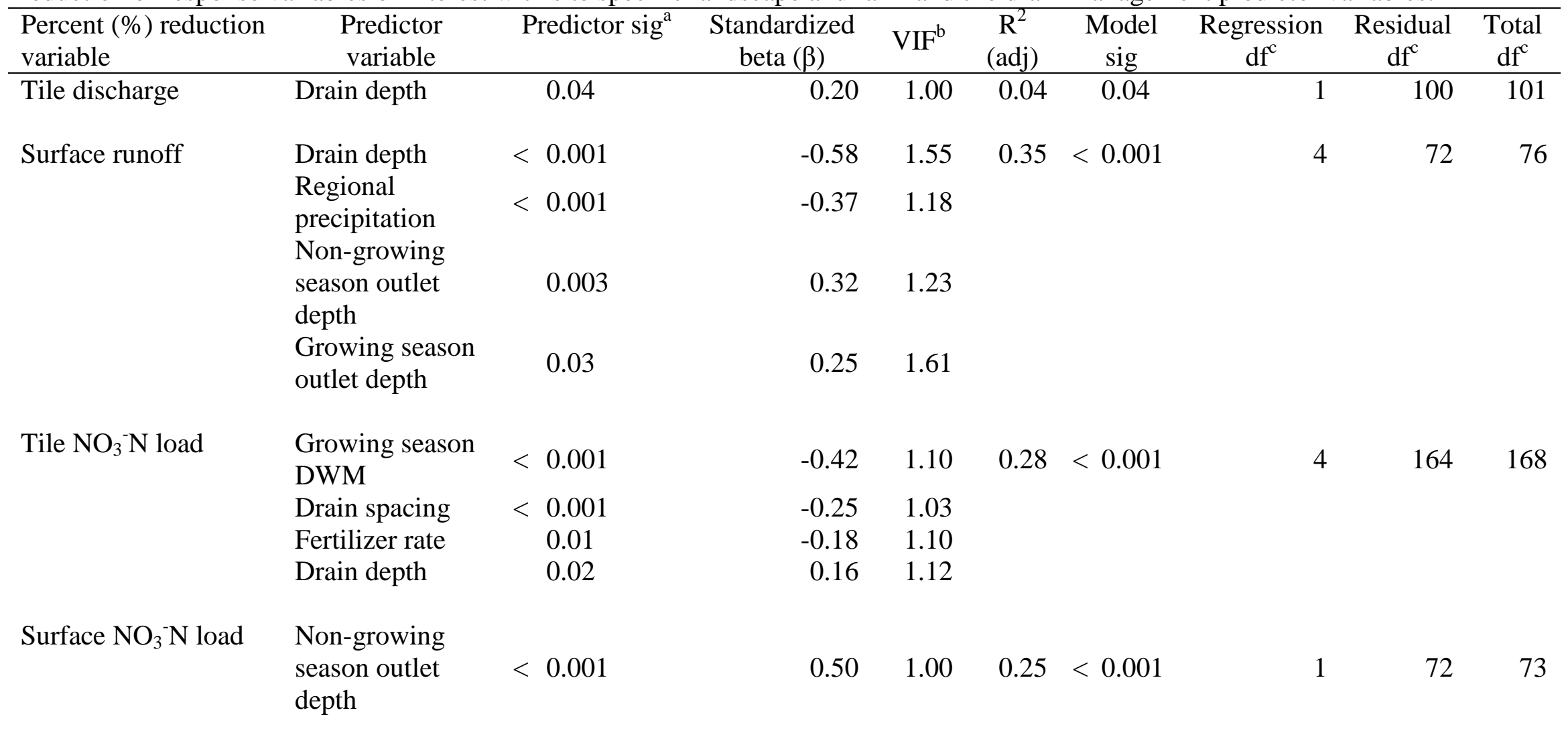

\footnotetext{
${ }^{\mathrm{a}}$ sig refers to statistical significance

${ }^{b}$ VIF refers to variance inflation factor

${ }^{c} \mathrm{df}$ refers to degrees of freedom
} 


\section{Figure captions}

Figure 1. Number of studies obtained for each response variable of interest.

Figure 2. Tile discharge volumes (a) and nitrate loads (b) for managed (DWM) and free draining (FD) treatments partitioned between growing and non-growing season data. Bars represent means \pm 1 standard error, and numbers in parentheses indicate the number of observations for each treatment.

Figure 3. Dissolved reactive phosphorus (DRP) and total phosphorus tile loads for managed (DWM) and free draining (FD) treatments. Bars represent \pm 1 standard error, numbers in parentheses indicate the number of observations for each treatment, and all data are from measured observations.

Figure 4. Univariate relationship between fertilizer application rate $(\mathrm{kg} / \mathrm{ha})$ and percent $(\%)$ reduction of tile $\mathrm{NO}_{3}{ }^{-} \mathrm{N}$ loads using only data from measured observations.

Figure 5. Partial regression plots of factors associated with percent (\%) reduction of tile $\mathrm{NO}_{3}{ }^{-} \mathrm{N}$ load when pooling measured and simulated observations together. Partial regression plots represent percent (\%) reduction of tile $\mathrm{NO}_{3}{ }^{-} \mathrm{N}$ as a function of (a) growing season DWM, (b) drain spacing, (c) fertilizer application rate, and (d) drain depth. Axes from partial regression plots should not be interpreted as real life values, but rather are a way to visualize relationships between the response variable with each predictor variable while holding all other predictors included in the model constant. 
Figure 1

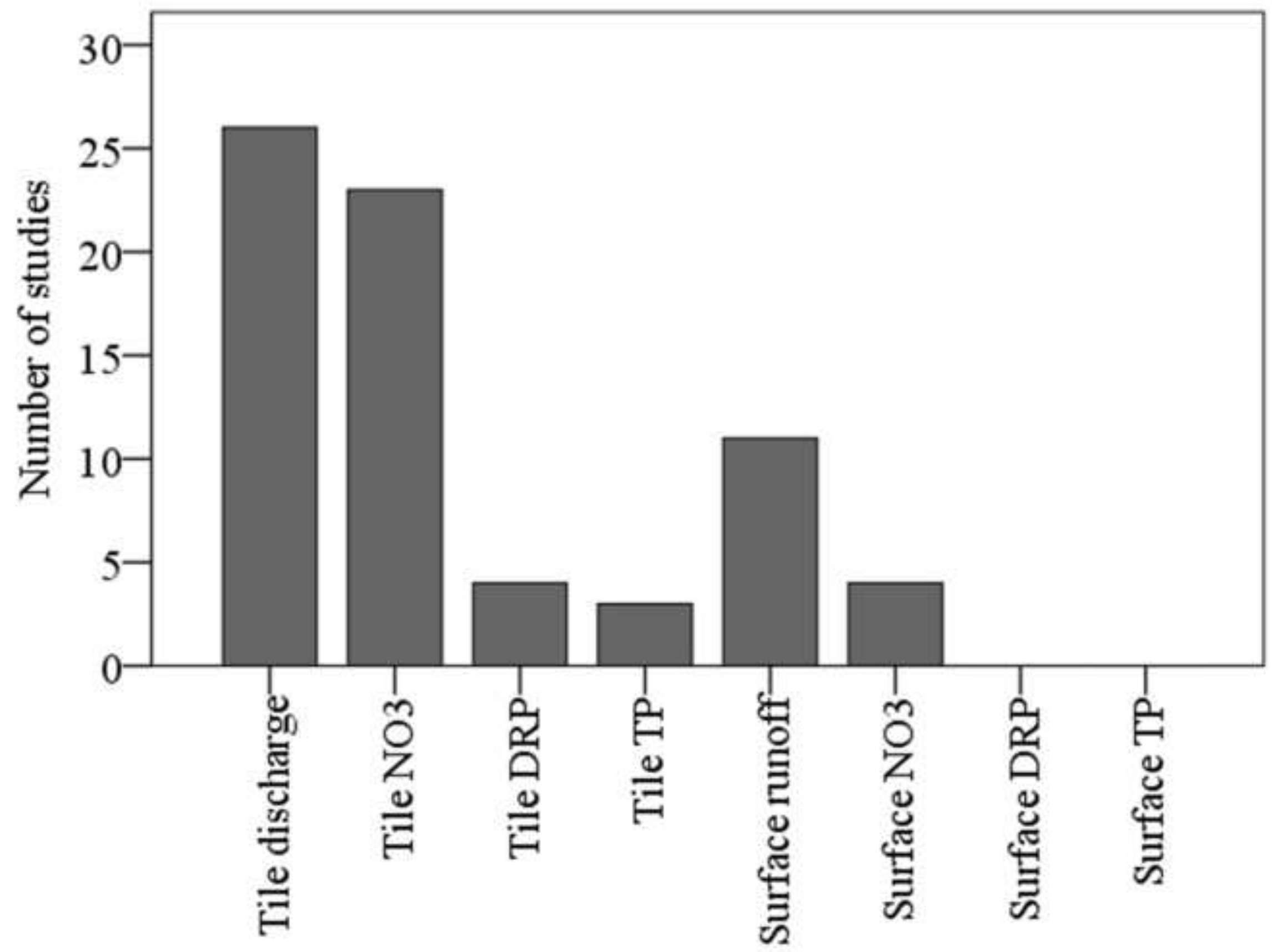

Pathway and variable 
Figure 2
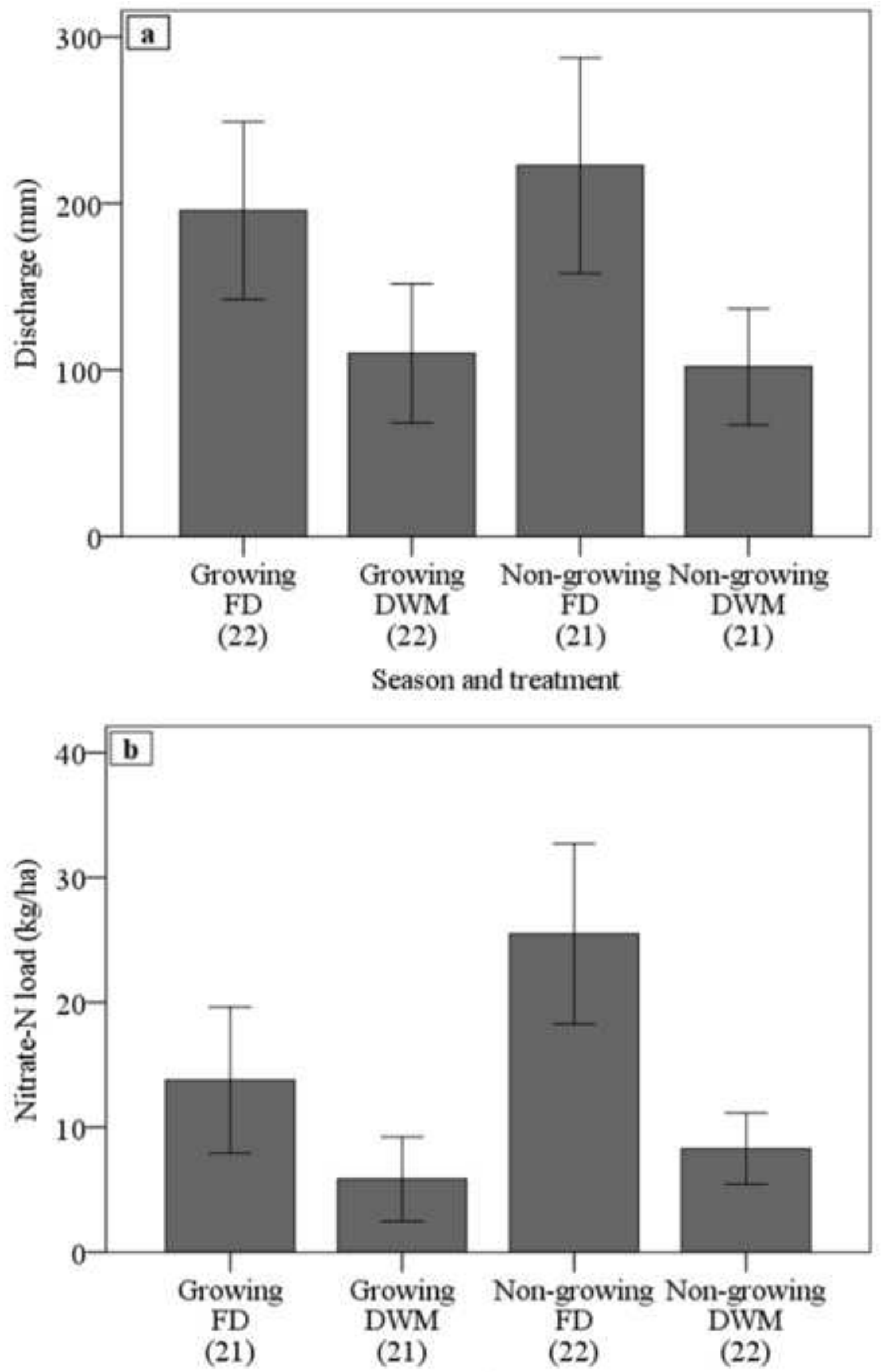

Season and treatment 


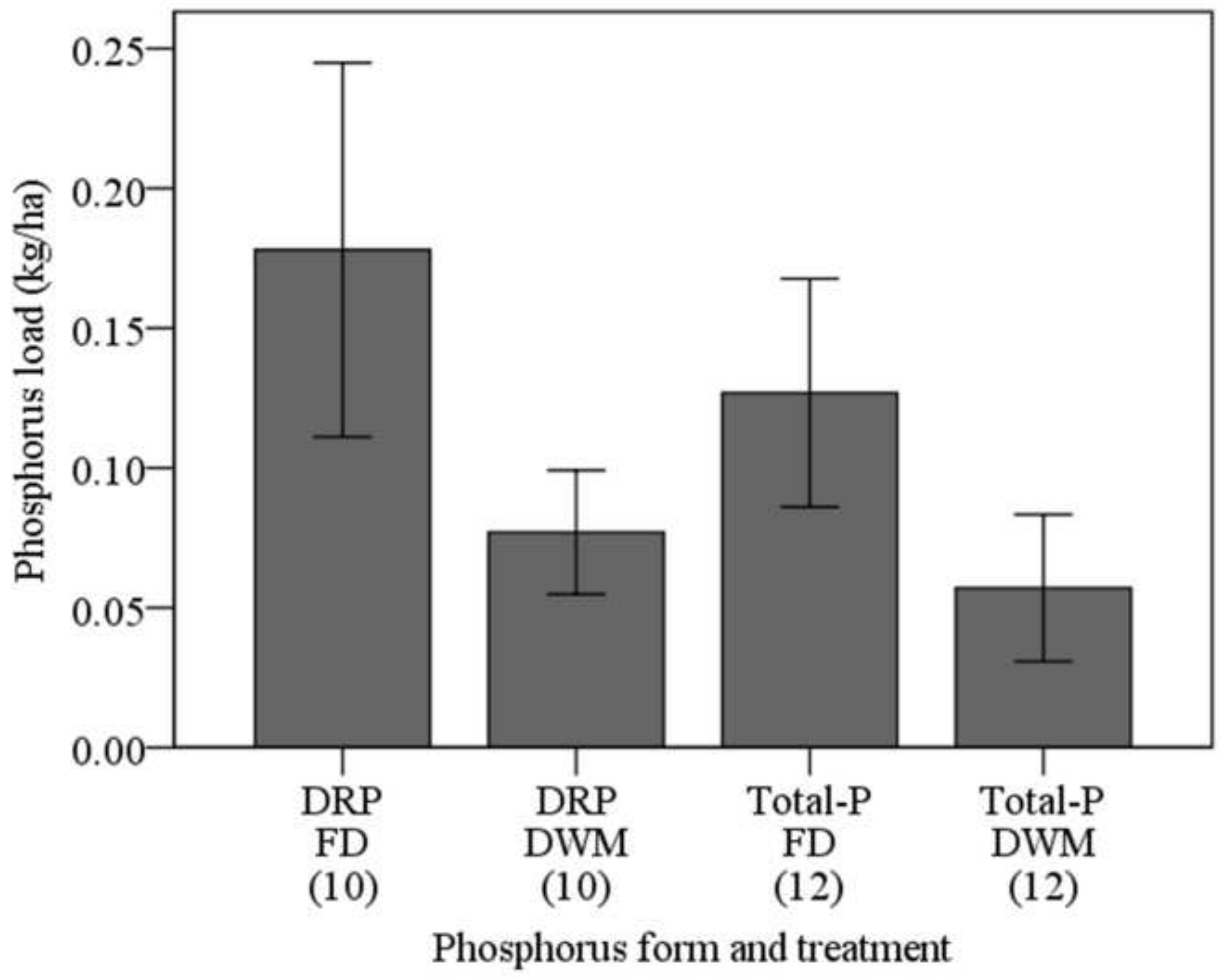




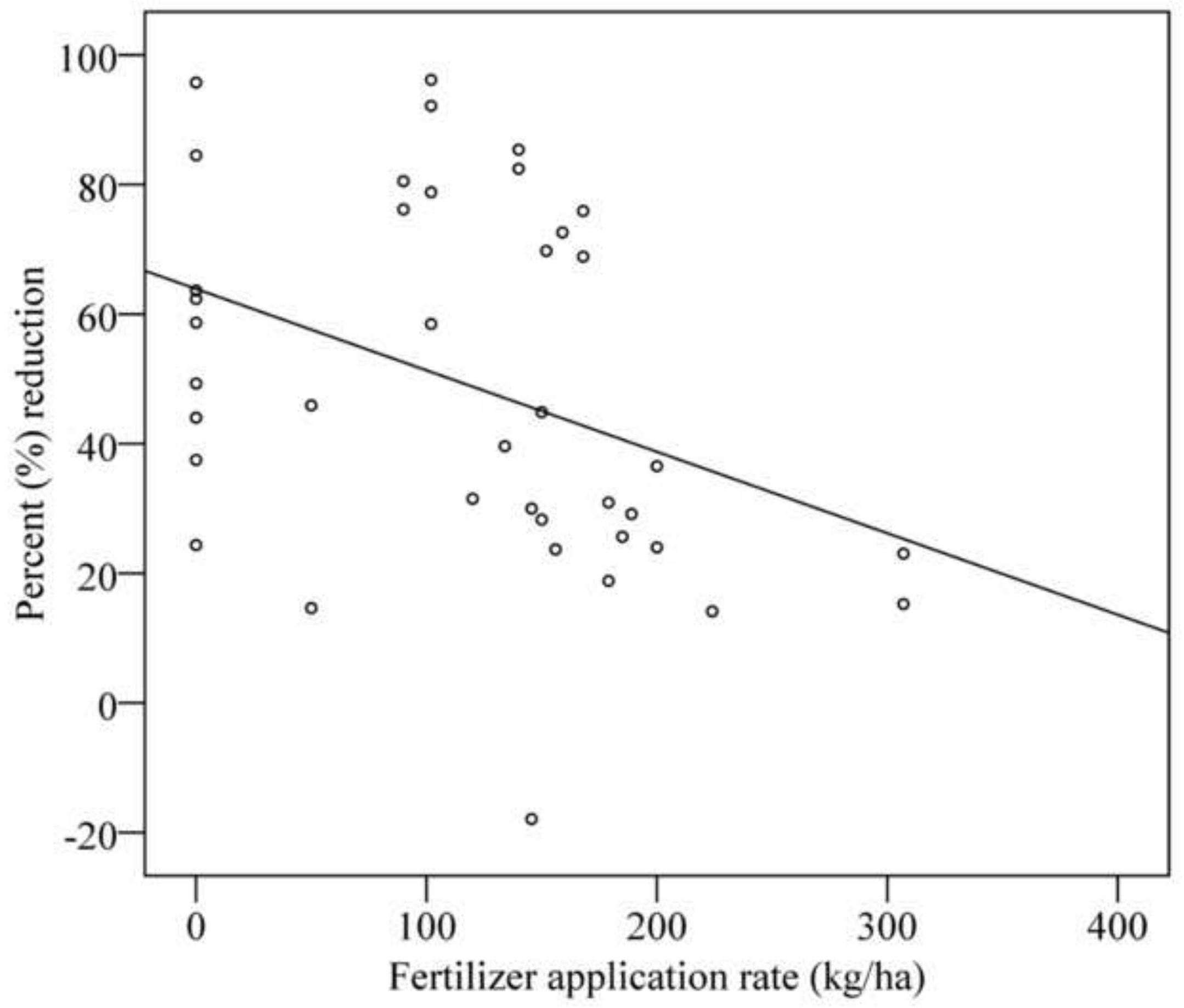



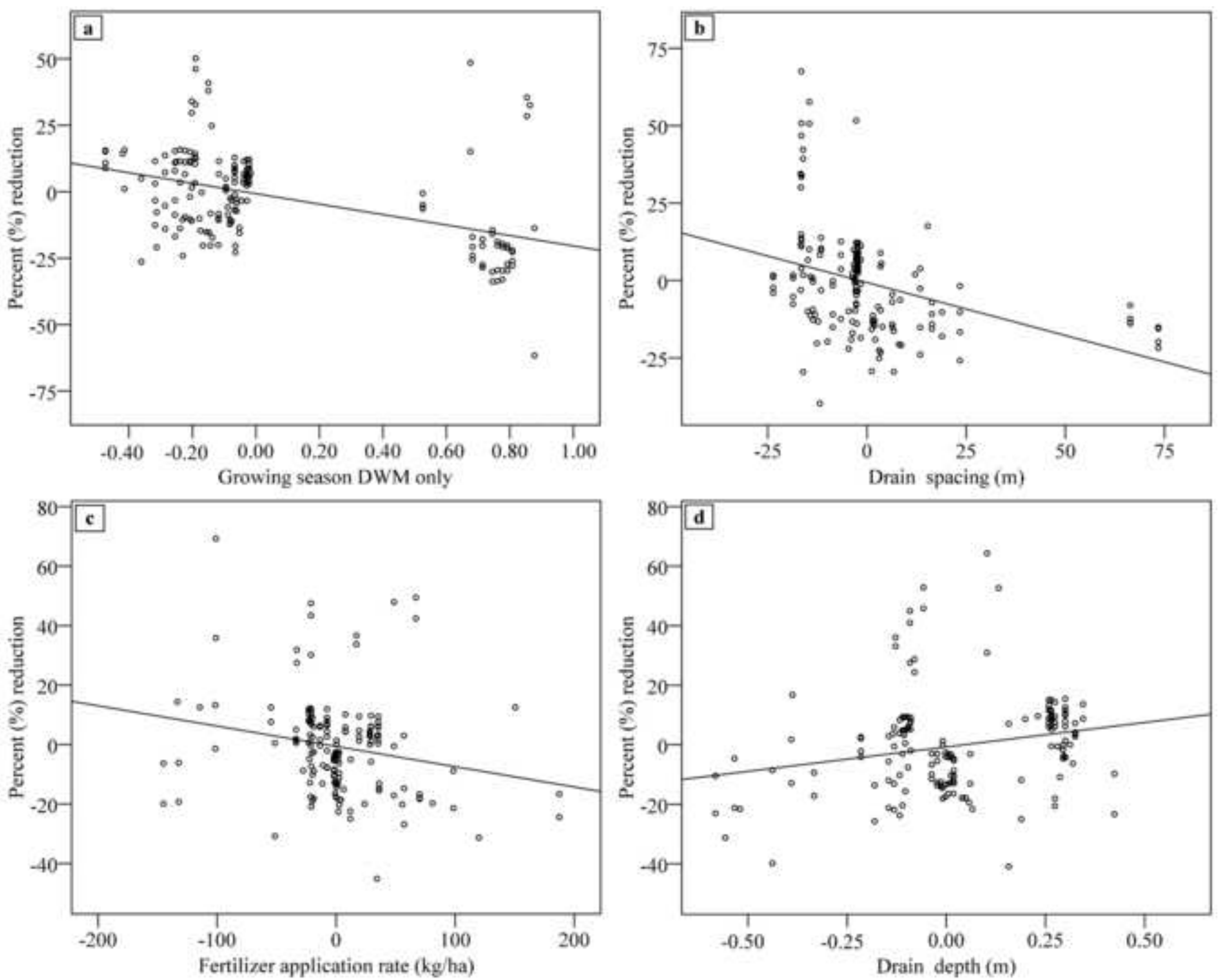


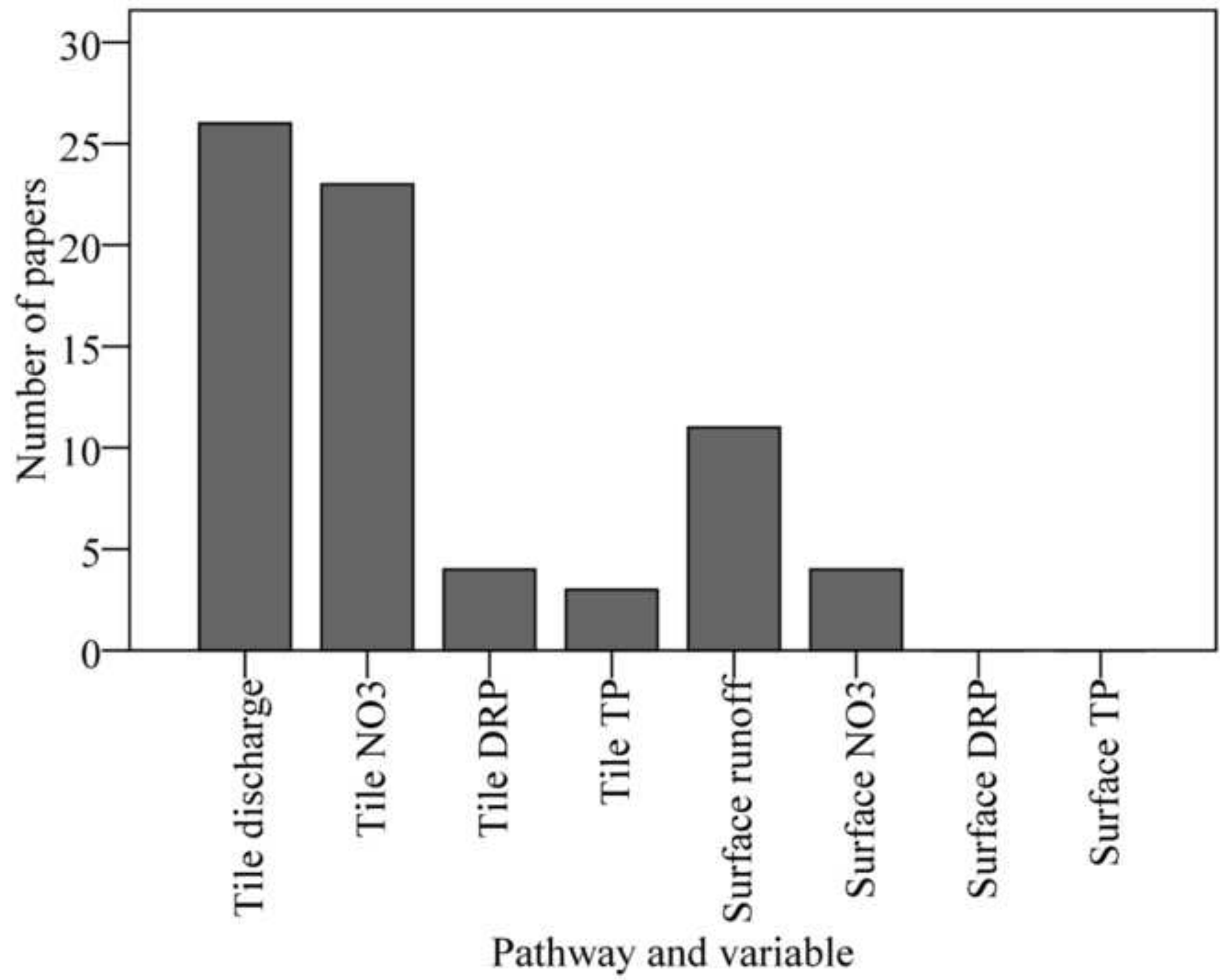


Figure 7
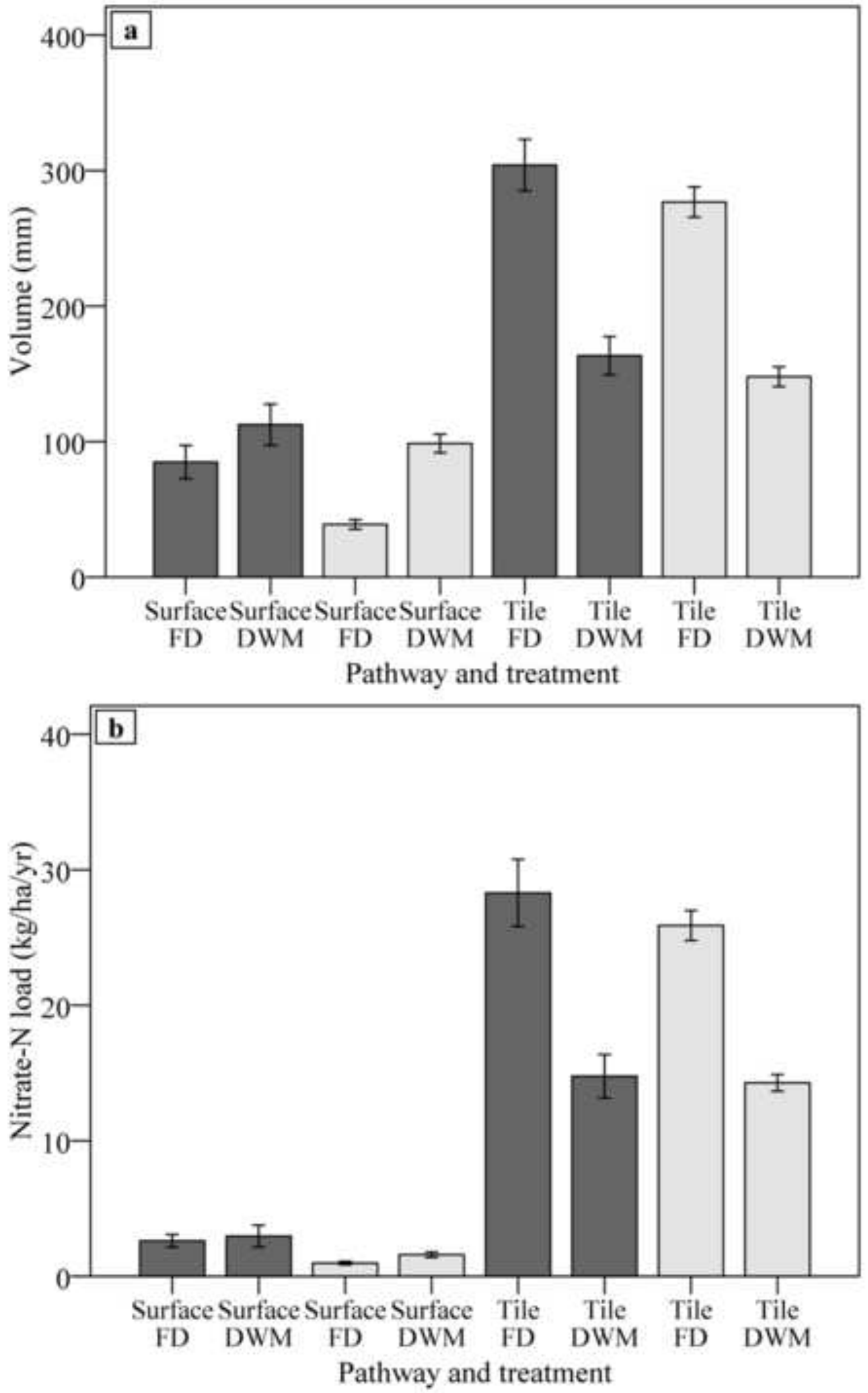


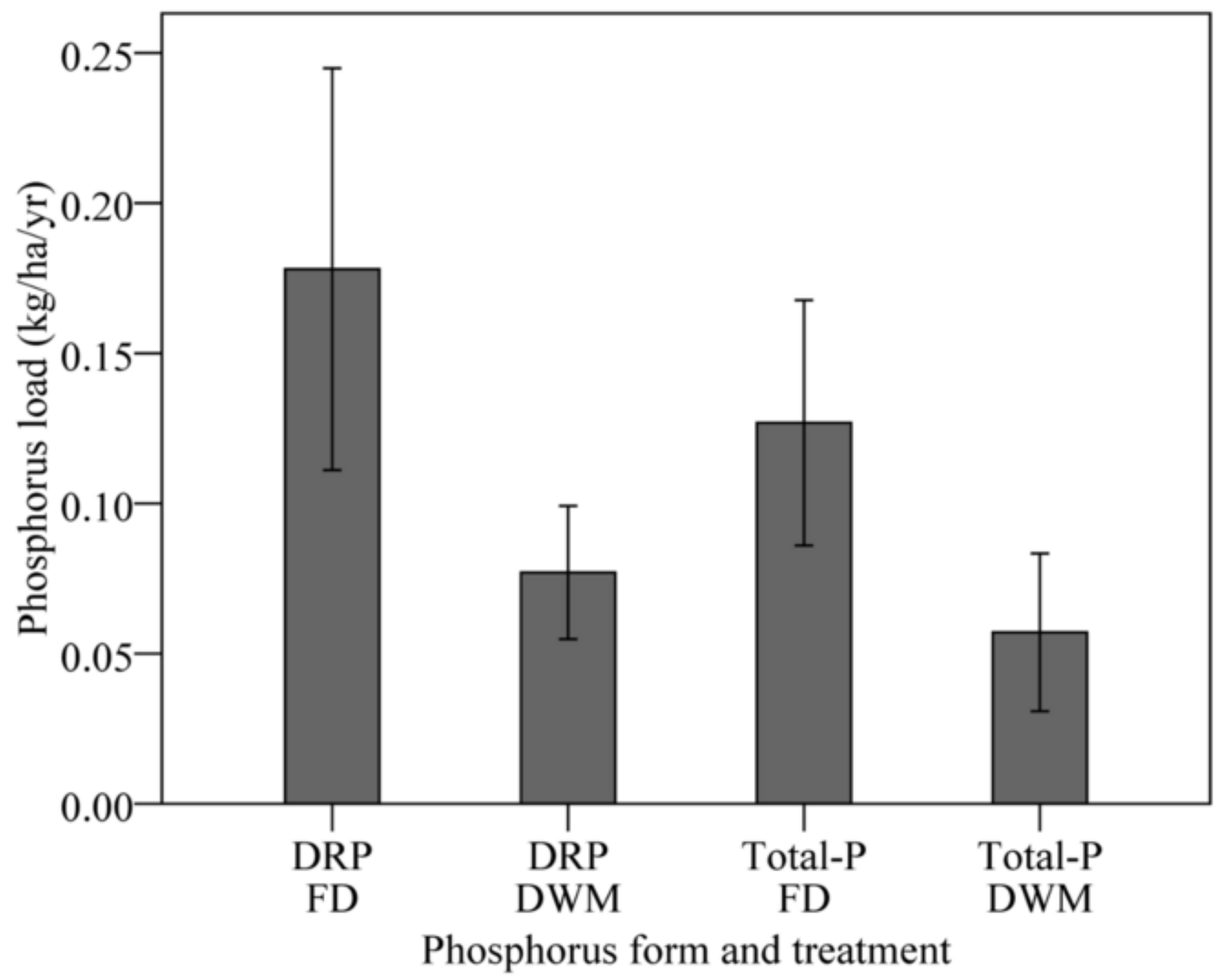

